\title{
Kingston's experience with Spanish influenza: explaining the highest death rate in Canada
}

\author{
Cite as: CMAJ 2019 April 1;191:E367-9. doi: 10.1503/cmaj.181166
}

$\mathrm{T}$ he Spanish influenza, a global flu outbreak that occurred in the fall and early winter of 1918 , remains one of the most distressing public health crises the world has endured. Not since the Black Death of 1346 had the world experienced such dramatically devastating illness; by most estimates, the global death toll during the Spanish flu was 20-50 million people. ${ }^{1}$ The debate as to the flu's origin continues. Some suggest it began on pig farms in the United States and spread through military camps, whereas others believe it began on poultry farms in China. ${ }^{2}$ Each community has a fascinating story of this 100 -year-old phenomenon.

A common measure in Canadian communities during the epidemic was to close public places to prevent its spread. ${ }^{3}$ A unique story comes from Kingston, Ontario, which was distinct in having Canada's highest death rate from influenza in 1918.

When the devastation from Spanish influenza eased in December 1918, Ontario's Provincial Health Officer, Dr. John McCullough, collected and published data on influenza deaths throughout Ontario and Canada. ${ }^{4}$ The greatest number of deaths occurred in Montréal (3128) and Toronto (1600), but Kingston had Canada's highest death rate at 644 deaths per 100000 population (Box 1).

To discuss the epidemic in Kingston, it is important to acknowledge 2 points. First, influenza was not a reportable disease in 1918. Communities tracked and recorded influenza and its complications differently, resulting in discrepancies among regions. Second, the primary data that McCullough used in his report have

\begin{tabular}{|c|c|c|c|}
\hline City & Population & $\begin{array}{l}\text { Deaths from influenza } \\
\text { and complications, } \\
\text { chiefly pneumonia }\end{array}$ & $\begin{array}{l}\text { Death rate per } \\
100000 \text { population }\end{array}$ \\
\hline Fort William & 18850 & 45 & 238 \\
\hline Sault Ste. Marie & 12829 & 41 & 319 \\
\hline Ottawa & 104000 & 570 & 548 \\
\hline Port Arthur & 15244 & 20 & 131 \\
\hline Windsor & 30000 & 32 & 106 \\
\hline Kingston & 22265 & 145 & 644 \\
\hline London & 57301 & 187 & 326 \\
\hline Toronto & 490000 & 1600 & 327 \\
\hline St. John & 42511 & 126 & 296 \\
\hline Winnipeg & 183595 & 388 & 211 \\
\hline Montréal & 640000 & 3128 & 489 \\
\hline Halifax & 46610 & 153 & 329 \\
\hline Hamilton & 104491 & 244 & 233 \\
\hline
\end{tabular}

not survived. Therefore, we are largely left with historical speculation about his interesting observations in Kingston. Why did this small city of 22000 people have such a high flu-related death rate? Important contributing factors may have included free medical care, the city's unique location and the establishment of medical infrastructure.

Patients could receive free medical care at Kingston General Hospital. The origin of free medical service began in 1854 when one of the city's first physicians, Dr. James Sampson, thought it wise to allow easy access for medical students at Queen's University to learn in a hospital setting. Before 1854, the year in which Queen's was allowed to grant medical degrees, physicians had privately trained medical students on the wards. With the opening of a medical school in Kingston, the hospital administration recognized that medical students might pay and, therefore, support the financially strapped hospital. Sampson's efforts resulted in a unique institutional relation between the university and the hospital - free medical care at Kingston General Hospital with medical students from Queen's attending to patients. ${ }^{5}$ Both sides benefitted: Queen's medical students gained access to patients on the wards and the hospital received an influx of medical personnel.

Free medical care likely drew patients to Kingston, but Kingston's geographic location necessitated their travel. At the confluence of the Great Lakes and 
St. Lawrence River, Kingston was the largest medical centre between Toronto and Ottawa. Margaret Angus, a Kingston historian, describes Kingston General Hospital at the time as drawing half its patients from within a 25 -mile radius, with the other half coming from beyond that area. ${ }^{5}$

The surge of more than 900 patients during the pandemic overwhelmed the small 200-bed hospital, which had been treating 3600 patients annually before the outbreak. As evidenced by the hospital's admissions and death registers at the time, travellers were commonly admitted only days before succumbing to the flu. It is likely that people from surrounding counties died more quickly than local citizens because their health had diminished substantially before they arrived in Kingston. ${ }^{6}$

Kingston had 3 permanent hospitals: Kingston General Hospital, Hotel Dieu Hospital and Rockwood Asylum. In response to both the war and pandemic, 5 additional temporary hospitals were established in Kingston.

As the largest hospital in the city, Kingston General Hospital received 902 admissions between October 1918 and February 1920, when the pandemic finally subsided. Of these admissions, $65.5 \%$ were for influenza or pneumonia (the flu's most common complication). Following the global trend, flu cases at the hospital affected otherwise healthy, young people, who averaged 22.3 years of age. During the peak of the flu in October and November 1918, $75 \%$ of deaths at the hospital (33 patients) were from the flu or its complications. Kingston's downtown hospital, Hotel Dieu Hospital, was likewise overwhelmed with 4 times more influenza cases in 1918 than in 1917. ${ }^{7}$ The situation at Hotel Dieu Hospital was much the same as at Kingston General Hospital, with overcrowding and overworked staff begging for more medical and financial support.

In 1914, the Canadian government reviewed requests from communities throughout the country to establish temporary hospitals for returning soldiers. It became apparent early in the war effort that Kingston's permanent hospitals could not handle the expected influx of

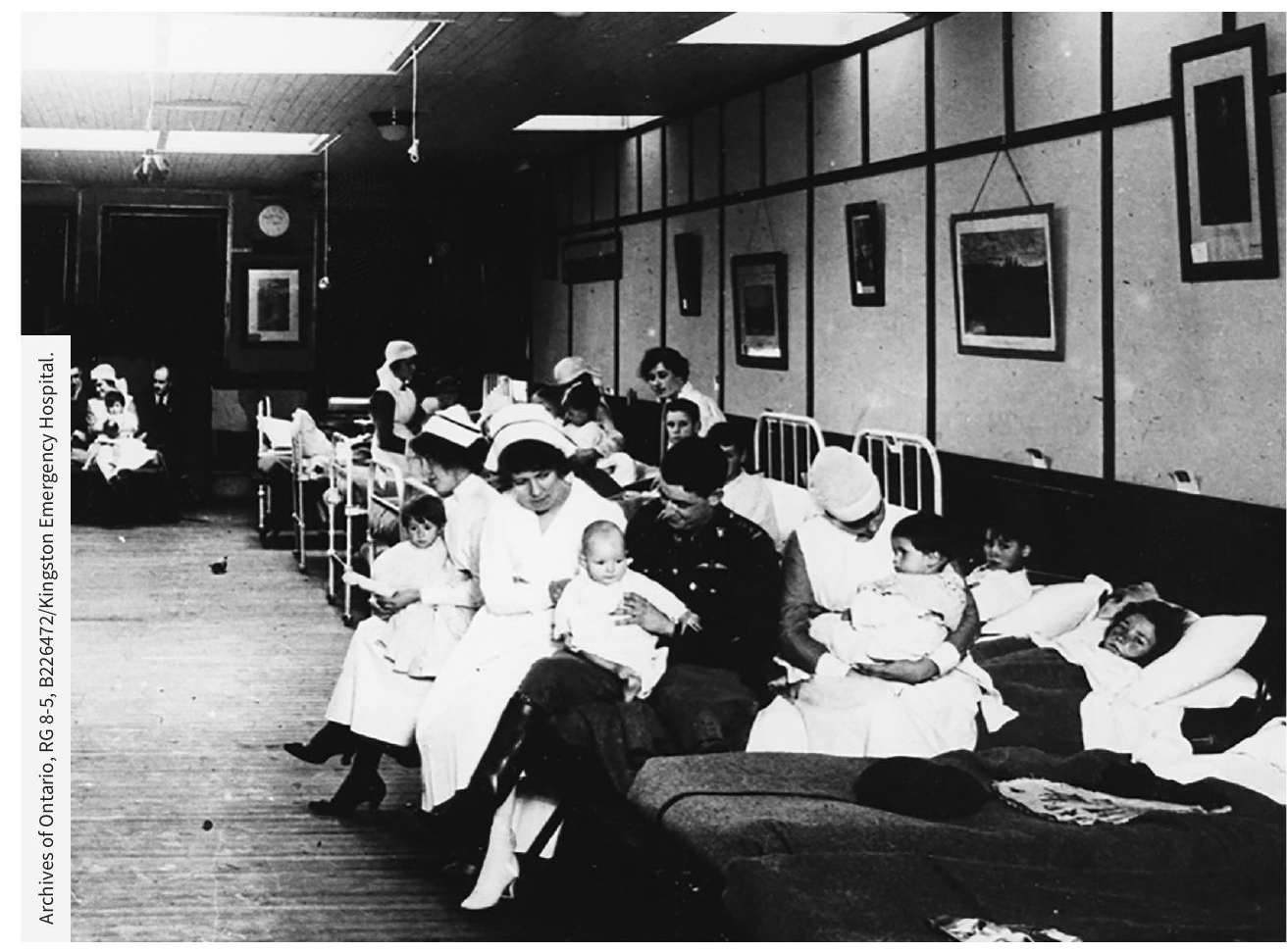

Figure 1: The Great War Veterans' Association Emergency Hospital situated at 67 Princess Street, Kingston, Ont. Twenty-two families were supported while the hospital was open from Oct. 19 to Nov. 7, 1918, treating women and their children. Correspondence of the Provincial Secretary. [1916-1919]/Copyright Public Domain.

soldiers adequately. In response, Queen's donated the adjoining Grant and Kingston Halls, which were jointly renamed Queen's Military Hospital.

Following its donation, Queen's Military Hospital was redesigned to increase the number of beds to 600 . In 1917, the military hospital opened its doors and eased the burden on Kingston General Hospital, soon serving the dual purpose of both a war and influenza hospital. From Oct. 1, 1918, to Feb. 29, 1919, 201 cases of influenza or pneumonia were admitted at Queen's Military Hospital. Admissions to the military hospital reached a peak between Oct. 7 and Oct. 21, as 141 new patients with the flu were admitted during that time. When a decree from Kingston's medical health officer was released on Oct. 16, 1918, stating that all public places were to be closed to prevent the flu's spread, Queen's Military Hospital remained open while the rest of the university shut down. ${ }^{8}$ Fourth-year medical students were granted accelerated graduation, skipped their fifth and final year, and were dispatched to help at local hospitals and in surrounding communities. ${ }^{9}$
Additional hospitals were established either as flu- or soldier-specific hospitals. The Great War Veterans' Association Emergency Hospital on Princess Street was a temporary hospital solely constructed for patients with influenza (Figure 1). It supported women and their children with the flu, treating 57 patients from 22 families, with 2 deaths. ${ }^{10}$ The temporary hospital shut down promptly after the flu's peak had passed, closing on Nov. 7, 1918. Two additional temporary hospitals, Ongwanada and Sydenham Military Hospitals, admitted 60 soldiers with the flu, 52 of whom were discharged to duty, 7 were transferred to regional hospitals and 1 died.

The story behind Kingston's high death rate, like so many stories of quantification, shows how standard representations of numbers can conceal a larger story. Although we may never know why McCullough decided to present his mortality data as he did, we can infer that free medical care, a central geographic location and 8 temporary and permanent hospitals brought a surge of people to Kingston during the 1918 influenza pandemic. 
Those patients who died in Kingston but whose residence was elsewhere contributed to Kingston's death toll but not the city's population; this phenomenon inaccurately increased the death rate. The result was not only a higher death rate than was reported for other Canadian centres but, indeed, a higher death rate than was experienced among native Kingstonians.

\section{Andrew Belyea BScH}

Queen's University School of Medicine, Kingston, Ont.

\section{References}

1. Patterson KD, Pyle GF. The geography and mortality of the 1918 influenza pandemic. Bull Hist Med 1991;65:4-21.

2. Oxford JS, Gill D. Unanswered questions about the 1918 influenza pandemic: origin, pathology, and the virus itself. Lancet Infect Dis 2018; 18:e348-54.

3. Humphries MO. The horror at home: the Canadian military and the "great" influenza pandemic of 1918. J Can Hist Assoc 2005;16:235-60. doi: 10.7202/015733ar.

4. McCullough JWS. The control of influenza in Ontario. Can Med Assoc J 1918;8:1084-6.

5. Angus M. Kingston General Hospital: a social and institutional history. 1st ed. Montréal: McGillQueens University Press; 1973.
6. Belyea A. The Spanish influenza: exploring Kingston's deadly pandemic of 1918. Kingston (ON): Museum of Health Care at Kingston; 2017.

7. Hotel Dieu Hospital Admission Registers, 1917-1919.

8. Theatres and schools will be shut tomorrow. Kingston Daily Standard 1918 Oct. 16;p. 1.

9. S.O.S. Queen's Journal 1918 Nov. 5;p. 3.

10. S.O.S. Report. Minutes of Kingston City Council. 1918 Nov. 23;p. 192.

This article has been peer reviewed.

Funding: Funding for this research was provided by the Museum of Health Care at Kingston through a Margaret Angus Research Fellowship. 